\title{
Preface
}

To date, the literature on corporate sustainability strategies has focused almost exclusively on companies operating in developed economies with strong markets and institutions. This book shows how companies operating in emerging economies (such as Latin America) characterized by market failure and weak institutions can improve their triple bottom line performance.

\section{THE STRUCTURE OF THE BOOK}

Part I provides the historical context and the philosophical underpinnings for the interest in sustainability. It introduces the 'sustainability frontier' as a key concept for determining whether or not a company needs to consider trade-offs between its financial, environmental and social objectives in developing and implementing its business strategy. It also relates sustainability to corporate social responsibility (CSR) and introduces the notion that corporate strategies must meet the tests of viability and legitimacy before they can be competitive.

Part II describes the sustainability challenges and opportunities for firms in Latin America. It shows how natural resources can be a curse as well as a blessing, and outlines the challenges and opportunities in accessing the vast underserved markets at the base of the pyramid. The influence of informal markets and of financial markets is considered, and the chapters describe how companies develop their strategies and progress from family businesses to strategically oriented governance structures.

Part III offers a number of sustainability models, including 'no-tradeoff', shared value, shared value clusters, sustainable supply chains and social business.

The conclusion focuses on how companies in Latin America can address their sustainability challenges and opportunities using the concepts described in this book to improve their triple bottom line performance.

Appendix 1 provides a brief description of a number of cases of companies in Latin America - where they are located relative to the sustainability frontier and how they are addressing their sustainability challenges. 
Appendix 2 includes data and analysis of the triple bottom line performance of 21 Latin American countries from 1990 to 2010.

\section{GENESIS}

This book grew out of the 'Think Forward Latin America Forum: Strategies, Solutions, Sustainability', held at INCAE Business School in Costa Rica on May 21-23, 2012. The Forum was convened by the two editors of this book, in collaboration with Silke Bucher and Lawrence Pratt: http://www.incae.edu/es/clacds/thinkforward/home/.

At the end of the conference, after its stimulating discussions, those who were interested in contributing to a book based on the conference met to talk about who wished to contribute what, and that is how it all began. Several other experts who were not present joined later as we embarked on this adventure together.

It was agreed from the beginning that all the royalties from the book would be donated to a worthy cause. The editors have chosen UNICEF as the charity that will receive all the royalties from the sale of this book. ${ }^{1}$

With the conference as the common experience of most of the authors, all the contributors to this book used two common reference points for writing their chapters: the 24 illustrative cases included throughout the book provided a common empirical reference point, and the concept of the 'sustainability frontier' provided a common analytical framework.

\section{ACKNOWLEDGMENTS}

We thank all the authors for their substantial contributions to this book, and we wish to acknowledge the special help and thoughtful guidance we received from several authors and a few others.

As we make clear in our Introduction in Chapter 1, Dennis Young made the breakthrough contribution of the 'sustainability frontier', which he develops more fully in his pivotal Chapter 2, and it became the integrating concept for the book as well as its sub-title. Dennis also served as our sounding board when difficult decisions had to be made, and provided wise counsel throughout. He and our friend Professor James Wiley of Hofstra University, a leading authority on the economic geography of Latin America, both provided critical input that helped us to develop the nomenclature for the 'sustainability map' that is featured throughout the book.

Chris Laszlo was another key advisor behind the scenes who also 
served as our sounding board, starting with the conference and continuing throughout. Like Dennis, he was among the first to develop his chapter fully, and these two completed chapters helped to propel the book forward faster than either of them may realize.

We were lucky to have Fernando Casado Cañeque to provide guidance and advice as well, and he was kind enough to take the time to prepare Chapter 3 for the book when we concluded that we needed this contribution in addition to his Chapter 5 on the base of the pyramid. We also appreciate the support of John Ickis, who not only wrote Chapter 9 together with Andrea Prado but also gave us his wise advice and guidance on Part II.

There are a few others whom we would like specifically to acknowledge. The work of Stuart Hart that he cites in his Foreword provided the intellectual inspiration for the Forum that spawned this book, and Stu and his work have remained a constant source of stimulation and support ever since. Equally, the institutions that Stephan Schmidheiny has built in the service of society, and his work as an author and an entrepreneur, have lighted a path that guided our journey. We feel most fortunate that these two pioneers in the quest for sustainability have taken the time to provide such thoughtful retrospectives as well as offering beacons for the future in their Forewords. We thank them both for their support and for these contributions.

We can trace our intellectual debt back even further to the work of Peter F. Drucker, who observed long ago that every environmental and social problem is a business opportunity in disguise. ${ }^{2}$ Although he did not live to see this book, both the editors have been deeply influenced by Drucker's work and one of us (Sathe) would also like to acknowledge the personal warmth and wisdom of the intellectual giant that he was so fortunate to have as a friend and colleague for over 20 years.

This book went through the blind review process at two other publishers before we signed the agreement with Edward Elgar Publishing. We want to thank our editor, Alan Sturmer, for his wise counsel and steady hand in converting our manuscript into a book. We also want to thank all prior reviewers and editors, who must necessarily remain anonymous, for their critical and thoughtful feedback along the way, which made the final product so much better.

There is no end to feedback and revisions, of course, because the learning goes on. At some point the two editors of this book had to say, 'That is enough, for now'! And with publication comes the opportunity to continue to learn as we get additional feedback from, we hope, a much wider circle of readers.

For the two editors of this book, this has been an amazing learning journey because we got to work with so many talented and accomplished 
xxviii

contributors from so many parts of the world. We dedicate this book to them, and to our wives, who made it all possible and worthwhile. It has been for the two of us from beginning to end a true joint venture to which we contributed equally and, in the process, became not only good colleagues but also good friends. 